\title{
PEMILIHAN BIBIT LELE UNGGUL DENGAN MENGGUNAKAN METODE WEIGHTED PRODUCT
}

\author{
Dasril Aldo ${ }^{1)}$ \\ ${ }^{1}$ Sistem Informasi, STMIK GICI, BATAM \\ email: dasrilaldo1994@gmail.com
}

\begin{abstract}
One method of computing that is quite developed today is the method of decision support systems. A decision support system is required in order to have the ability to process a fast, targeted, and accountable in generating a decision. In the breeding and cultivation of catfish there are types of catfish seedlings are superior and not superior seeds, where the fish seeds should be selected and separated between superior and not superior. In the process of selecting superior catfish seedlings, the right selection mechanism is needed in order to produce the appropriate decisions as expected. The result of this research is the development of decision support system that can help the cultivation of catfish produce decision about the type of superior fish seedlings quickly and precisely.
\end{abstract}

Keywords: Decisions Support System, Weighted Product, Catfish

\section{Abstrak}

Salah satu metode komputasi yang cukup berkembang saat ini adalah metode sistem pendukung keputusan. Suatu sistem pendukung keputusan dituntut agar dapat mempunyai kemampuan proses yang cepat, tepat sasaran, dan dapat dipertanggung jawabkan dalam menghasilkan suatu keputusan. Dalam pembibitan dan budi daya ikan lele terdapat jenis bibit ikan lele yaitu jenis bibit unggul dan tidak unggul, dimana bibit ikan tersebut harus diseleksi dan dipisahkan antara yang unggul dan yang tidak unggul. Dalam proses pemilihan bibit ikan lele yang unggul maka diperlukannya mekanisme pemilihan yang tepat agar dapat menghasilkan keputusan yang sesuai dengan yang diharapkan. Hasil dari penelitian ini adalah terbangunnya sistem pendukung keputusan yang dapat membantu pihak pembudidayaan ikan lele menghasilkan keputusan mengenai jenis bibit ikan yang unggul dengan cepat dan tepat.

Kata Kunci: Sistem pendukung keputusan, Weighted Product, Ikan lele

\section{PENDAHULUAN}

Teknologi dibidang sistem informasi pada saat ini sangat maju dengan pesat sekali baik dari sisi kecepatan maupun kemudahan masyarakat untuk mengakses informasi. Perkembangan ini dapat juga kita lihat dengan banyaknya perangkat baru baik itu dari hardware maupun software yang terus menerus bermunculan serta membantu menyelesaikan permasalahan-permasalahan diberbagai bidang. Diantarantanya sistem pendukung keputusan (Decisions Support System) berbasis komputer, sistem ini adalah sistem berbasis komputer yang dirancang untuk membantu pangambil keputusan dalam memecahkan masalah.

Sistem Pendukung Keputusan atau dikenal dengan SPK merupakan bagian dari sistem informasi yang berbasis komputer. Terdapat beberapa tahapan dalam sistem pendukung 
Hal : $15-23$

keputusan yaitu mendefinisikan masalah, pengumpulan data yang relevan dan sesuai, pengolahan data menjadi informasi, dan menentukan alternatif solusi. Sistem ini membantu mendukung dalam pengambilan keputusan pada seseorang dan organisasi baik perusahaan maupun instansi. Sistem pendukung keputusan dapat memberikan alternatif solusi bila seseorang atau sekelompok orang sulit dalam menentukan keputusan yang tepat dan sesuai.

Dengan Sistem pendukung keputusan diharapkan dapat memberikan informasi yang nantinya akan memberikan alternatif solusi pada masalah yang terjadi. Sistem pendukung keputusan memerlukan metode untuk mencari alternatif solusinya, beberapa metode yang dipakai salah satunya adalah Weighted Product atau (WP). Weighted Product adalah metode penyelesaian dengan menggunakan perkalian untuk menghubungkan rating atribut, dimana rating harus dipangkatkan terlebih dahulu dengan bobot atribut yang bersangkutan. Proses ini sama dengan halnya dengan proses normalisasi [1].

Dalam bidang budidaya perikanan juga tidak lepas dari masalah yang mengharuskan setiap orang terlibat didalamnya untuk mengambil sebuah keputusan terkait permasalahan tersebut. Permasalahan yang kerap dialami yaitu dalam penentuan pemilihan bibit ikan yang unggul yang akan dibudidayakan.Sistem Pendukung Keputusan pemilihan bibit unggul ini dapat memberikan informasi mengenai bagaimana pemilihan bibit yang unggul pada ikan lele, serta membantu peternak dalam pengambilan keputusannya.

Ikan lele merupakan jenis ikan yang mudah dipelihara. Kondisi air seperti apapun dapat dijadikan media pembesaran ikan lele. Ikan lele yang kemudian akan dibudidayakan memang menentukan tingkat dalam kesuksesan atau keberhasilan dari budidaya ikan lele. Jika salah dalam memilih bibit, maka usaha budidaya ikan dapat mengalami kegagalan.

Oleh karena itu, sangat penting dibangun sebuah sistem pendukung keputusan yang terkomputerisasi yang dapat memudahkan dalam memilih bibit ikan yang unggul sesuai dengan kebutuhan dan kriteria pada ikan dengan menggunakan metode Weighted product (WP). Penelitian ini menggunakan metode Weighted Product karena metode ini merupakan salah satu metode penyelesaian multi kriteria dimana dalam pemilihan bibit ikan yang unggul mempunyai banyak kriteria yang harus di pertimbangkan.

\section{TINJAUAN PUSTAKA}

\section{$2.1 \mathrm{SPK}$}

Sistem Pendukung Keputusan adalah sistem yang berbasis komputer yang dapat membantu pengambilan keputusan untuk memecahkan masalah tertentu dengan memanfaatkan data dan model tertentu. Turban (1990) dan Turban \& Aronson (2001) menyebutkan bahwa konsep sistem penunjang kaputusan (SPK) muncul pertama kali pada tahun 1970-an oleh Scott-Morton. .(Prof. Dr. Ir Marimin,MSc : 1). Mereka mendefenisikan sistem sebagai suatu sistem interaktif berbasis komputer yang dapat membantu para pengambil keputusan dalam menggunakan data dan model untuk memecahkan masalah yang bersifat tdak terstruktur [2].

Pada dasarnya SPK merupakan pengembangan lebih lanjut dari Sistem Informasi Manajemen terkomputerisasi yang dirancang sedemikian rupa sehingga bersifat interaktif dengan pemakainya. Interaktif dengan tujuan untuk memudahkan integrasi antara berbagai komponen dalam proses pengambilan keputusan seperti prosedur, kebijakan, analisis, pengalaman dan wawasan manajer untuk mengambil keputusan yang lebih baik. [3]. 
Hal : $15-23$

\section{$2.2 \mathrm{WP}$}

Weighted Product (WP) adalah keputusan analisis multi kriteria yang popular dan merupakan metode pengambilan keputusan multi kriteria. Metode Weighted Pruduct (WP) adalah himpunan berhingga dari alternaif keputusan yang dijelaskan dalam istilah beberapa kriteria keputusan. Metode Weighted Product (WP) mengunakan perkalian rating atribut, di nama setiap rating atribut harus dipangkatkan dulu dengan bobot atribut yang bersangkutan [4].

\subsection{Ikan Lele}

Ikan lele merupakan salah satu komoditas budidaya yang memiliki berbagai kelebihan, diantaranya adalah pertumbuhan cepat dan memiliki kemampuan beradaptasi terhadap lingkungan yang tinggi. Menurut Soares (2011) permintaan ikan lele mengalami peningkatan dari tahun ke tahun. Hal ini menyebabkan produksi ikan lele juga mengalami peningkatan. Produksi ikan lele nasional selama 2010-2014 rata-rata meningkat sebesar $35 \%$ per tahun yakni pada tahun 2010 sebesar 270.600 ton dan meningkat pada tahun 2014 sebesar 900.000 ton [5].

\section{METODE PENELITIAN}

Metode penelitian atau metode ilmiah adalah prosedur atau langkah-langkah dalam mendapatkan pengetahuan ilmiah atau ilmu. Jadi metode penelitian adalah cara sistematis untuk menyusun ilmu pengetahuan. Sedangkan teknik penelitian adalah cara untuk melaksanakan metode penelitian.

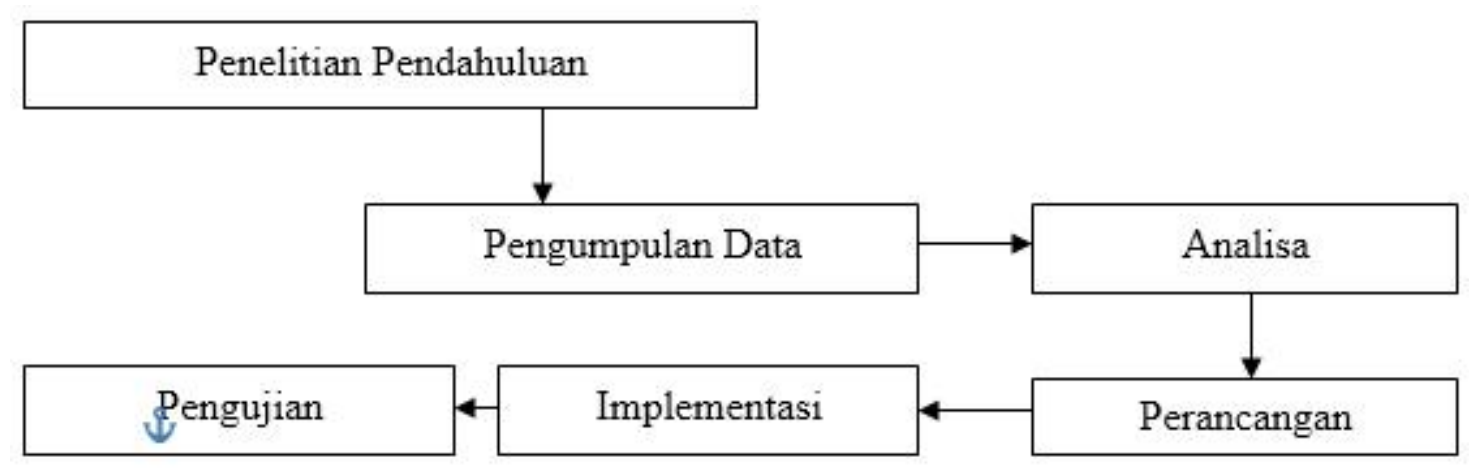

\section{Gambar 1. Metodologi Penelitian}

\section{HASIL DAN PEMBAHASAN}

Proses penganalisaan data yaitu dimana data tersebut berupa kriteria-kriteria yang digunakan sebagai penilaian terhadap pemilihan bibit unggul pada ikan lele. Adapun metode yang digunakan dalam menganalisa data ini adalah dengan menerapkan metode weighted product supaya menghasilkan informasi berupa perangkingan terhadap kriteriakriteria data yang dikelola tadi.

Berikut adalah kriteria yang digunakan dalam sistem pendukung keputusan ini. 
Hal : $15-23$

1. Menentukan Kriteria

\begin{tabular}{|c|c|c|c|c|}
\hline Kode & Kriteria & $\begin{array}{c}\text { Bobot } \\
\text { Kriteria }\end{array}$ & Penilaian & Bobot \\
\hline K1 & Pergerakan Ikan & 9 & $\begin{array}{l}\text { Sangat Lincah } \\
\text { Lincah } \\
\text { Lambat } \\
\text { Sangat Lambat }\end{array}$ & $\begin{array}{l}7 \\
5 \\
3 \\
1\end{array}$ \\
\hline $\mathrm{K} 2$ & Nafsu Makan Ikan & 2 & $\begin{array}{l}\text { Sangat Baik } \\
\text { Baik } \\
\text { Kurang Baik } \\
\text { Sangat Buruk }\end{array}$ & $\begin{array}{l}1 \\
3 \\
5 \\
7\end{array}$ \\
\hline $\mathrm{K} 3$ & Pernapasan Ikan & 7 & $\begin{array}{c}\text { Sangat teratur } \\
\text { Teratur } \\
\text { Sanga Tidak teratur } \\
\end{array}$ & $\begin{array}{l}7 \\
3 \\
1 \\
\end{array}$ \\
\hline K4 & Bentuk Tubuh Ikan & 6 & $\begin{array}{c}\text { Ideal } \\
\text { Kurang Ideal } \\
\text { Sangat Tidak Ideal }\end{array}$ & $\begin{array}{l}7 \\
5 \\
1 \\
\end{array}$ \\
\hline K5 & Kondisi Tubuh & 7 & $\begin{array}{l}\text { Sangat Bagus Tanpa Lecet } \\
\text { Tidak Bagus, Ada Lecet }\end{array}$ & $\begin{array}{l}7 \\
1 \\
\end{array}$ \\
\hline K6 & Kondisi Kulit Ikan & 4 & $\begin{array}{c}\text { Sangat Bagus } \\
\text { Terdapat Bercak jamur }\end{array}$ & $\begin{array}{l}7 \\
1\end{array}$ \\
\hline K7 & $\begin{array}{l}\text { Kondisi Mulut } \\
\text { Ikan }\end{array}$ & 5 & $\begin{array}{l}\text { Sangat Bagus, Tidak Terluka } \\
\text { Ada Luka }\end{array}$ & $\begin{array}{l}7 \\
1\end{array}$ \\
\hline $\mathrm{K} 8$ & Mata Ikan & 6 & $\begin{array}{c}\text { Sangat Baik } \\
\text { Baik } \\
\text { Tampak Berselaput } \\
\end{array}$ & $\begin{array}{l}7 \\
3 \\
1 \\
\end{array}$ \\
\hline K9 & Kumis Ikan & 3 & $\begin{array}{c}\text { Lengkap } 4 \text { Pasang } \\
\text { Kurang } 1 \\
\text { Kurang } 1 \text { Pasang atau lebih } \\
\end{array}$ & $\begin{array}{l}7 \\
3 \\
1 \\
\end{array}$ \\
\hline
\end{tabular}

2. Contoh Kasus

Berikut adalah contoh kasus dalam penelitian ini:

Tabel 2. Contoh Kasus

\begin{tabular}{|c|c|c|c|}
\hline NO & Kode Ikan & Kriteria & Penilaian \\
\hline 1 & IK 001 & K1 & Sangat Lincah \\
\hline & & K2 & Baik \\
\hline & & K3 & Teratur \\
\hline & & K4 & Sangat Bagus \\
\hline & & K5 & Sangat Bagus \\
\hline & & K6 & Sangat Bagus, Tidak Terluka \\
\hline & & K7 & Sangat Baik \\
\hline & & K8 & Sangat Lincah \\
\hline & & K9 & Sangat Baik \\
\hline & IK_002 & K1 & Teratur \\
\hline & & K2 & Ideal \\
\hline & & K3 & K4 \\
\hline & & &
\end{tabular}


Hal : $15-23$

\begin{tabular}{|c|c|c|c|}
\hline & & K5 & Sangat Bagus \\
\hline & & K6 & Sangat Bagus \\
\hline & & K7 & Sangat Bagus, Tidak Terluka \\
\hline & & K8 & Baik \\
\hline & & K9 & Lengkap 4 Pasang \\
\hline \multirow[t]{9}{*}{3} & IK 003 & K1 & Lincah \\
\hline & & $\mathrm{K} 2$ & Baik \\
\hline & & K3 & Teratur \\
\hline & & K4 & Kurang Ideal \\
\hline & & K5 & Bagus \\
\hline & & K6 & Sangat Bagus \\
\hline & & K7 & Sangat Bagus, Tidak Terluka \\
\hline & & K8 & Sangat Baik \\
\hline & & K9 & Kurang 1 \\
\hline \multirow[t]{9}{*}{4} & IK_004 & K1 & Sangat Lincah \\
\hline & & $\mathrm{K} 2$ & Sangat Baik \\
\hline & & K3 & Teratur \\
\hline & & K4 & Kurang Ideal \\
\hline & & K5 & Sangat Bagus \\
\hline & & K6 & Bagus \\
\hline & & K7 & Ada Luka \\
\hline & & K8 & Sangat Baik \\
\hline & & K9 & Lengkap 4 Pasang \\
\hline \multirow[t]{9}{*}{5} & IK 005 & K1 & Sangat Lincah \\
\hline & & $\mathrm{K} 2$ & Baik \\
\hline & & K3 & Teratur \\
\hline & & K4 & Ideal \\
\hline & & K5 & Bagus \\
\hline & & K6 & Sangat Bagus \\
\hline & & K7 & Sangat Bagus, Tidak Terluka \\
\hline & & K8 & Baik \\
\hline & & K9 & Lengkap 4 Pasang \\
\hline \multirow[t]{9}{*}{6} & IK_ 006 & K1 & Lambat \\
\hline & & $\mathrm{K} 2$ & Baik \\
\hline & & K3 & Teratur \\
\hline & & K4 & Kurang Ideal \\
\hline & & K5 & Sangat Bagus \\
\hline & & K6 & Sangat Bagus \\
\hline & & K7 & Sangat Bagus, Tidak Terluka \\
\hline & & K8 & Sangat Baik \\
\hline & & K9 & Lengkap 4 Pasang \\
\hline \multirow[t]{6}{*}{7} & IK 007 & K1 & Sangat Lincah \\
\hline & & $\mathrm{K} 2$ & Kurang Baik \\
\hline & & K3 & Sangat tidak teratur \\
\hline & & K4 & Kurang Ideal \\
\hline & & K5 & Sangat Bagus \\
\hline & & K6 & Sangat Bagus \\
\hline
\end{tabular}


Hal : $15-23$

\begin{tabular}{|c|c|c|c|}
\hline & & K7 & Sangat Bagus, Tidak Terluka \\
\hline & & K8 & Sangat Baik \\
\hline & & K9 & Lengkap 4 Pasang \\
\hline
\end{tabular}
berikut:

Selanjutnya dilakukan perubaha penilaian tersebut dalam bentuk nilai angka, seperti

Tabel 3. Perubahan Nilai Ke Angka

\begin{tabular}{|c|c|c|c|c|c|c|c|}
\hline NO & Kode & Kriteria & Penilaian & NO & Kode & Kriteria & Penilaian \\
\hline \multirow[t]{9}{*}{1} & IK_ 001 & K1 & 7 & 2 & IK 002 & K1 & 7 \\
\hline & & $\mathrm{K} 2$ & 3 & & & $\mathrm{~K} 2$ & 1 \\
\hline & & K3 & 3 & & & K3 & 3 \\
\hline & & K4 & 3 & & & K4 & 7 \\
\hline & & K5 & 7 & & & K5 & 7 \\
\hline & & K6 & 7 & & & K6 & 7 \\
\hline & & K7 & 7 & & & K7 & 7 \\
\hline & & K8 & 7 & & & K8 & 3 \\
\hline & & K9 & 1 & & & K9 & 1 \\
\hline \multirow[t]{9}{*}{3} & IK 003 & K1 & 5 & 4 & IK 004 & K1 & 7 \\
\hline & & K2 & 3 & & & $\mathrm{~K} 2$ & 1 \\
\hline & & K3 & 3 & & & K3 & 3 \\
\hline & & K4 & 5 & & & K4 & 5 \\
\hline & & K5 & 7 & & & K5 & 7 \\
\hline & & K6 & 7 & & & K6 & 7 \\
\hline & & K7 & 7 & & & K7 & 1 \\
\hline & & K8 & 7 & & & K8 & 7 \\
\hline & & K9 & 3 & & & K9 & 7 \\
\hline \multirow[t]{9}{*}{5} & IK_005 & K1 & 7 & 6 & IK_006 & K1 & 3 \\
\hline & & K2 & 3 & & & K2 & 3 \\
\hline & & K3 & 3 & & & K3 & 3 \\
\hline & & K4 & 7 & & & K4 & 5 \\
\hline & & K5 & 7 & & & K5 & 7 \\
\hline & & K6 & 7 & & & K6 & 7 \\
\hline & & K7 & 7 & & & K7 & 7 \\
\hline & & K8 & 3 & & & K8 & 7 \\
\hline & & K9 & 7 & & & K9 & 7 \\
\hline \multirow[t]{7}{*}{7} & IK 007 & K1 & 7 & & & & \\
\hline & & K2 & 5 & & & & \\
\hline & & K3 & 1 & & & & \\
\hline & & K4 & 5 & & & & \\
\hline & & K5 & 7 & & & & \\
\hline & & K6 & 7 & & & & \\
\hline & & K7 & 7 & & & & \\
\hline
\end{tabular}


Hal : $15-23$

\begin{tabular}{|l|l|l|l|l|l|l|l|}
\hline & & K8 & 7 & & & & \\
\hline & & K9 & 7 & & & & \\
\hline
\end{tabular}

Setelah dilakukan perubahan angka tehadap masing-masing kriteria, makakan dilakukan proses perbaikan bobot sebagai berikut:

$$
\begin{aligned}
& W n=\frac{W n}{w 1+w 2+w 3+w 4+w 5+w 6+w 7+w 8+w 9} \\
& W 1=\frac{9}{9+2+7+6+7+4+5+6+3}=0,142 \\
& W 2=\frac{2}{9+2+7+6+7+4+5+6+3}=0,040 \\
& W 3=\frac{7}{9+2+7+6+7+4+5+6+3}=0,142 \\
& W 4=\frac{6}{9+2+7+6+7+4+5+6+3}=0,122 \\
& W 5=\frac{7}{9+2+7+6+7+4+5+6+3}=0,142 \\
& W 6=\frac{4}{9+2+7+6+7+4+5+6+3}=0,081 \\
& W 7=\frac{5}{9+2+7+6+7+4+5+6+3}=0,102 \\
& W 8=\frac{6}{9+2+7+6+7+4+5+6+3}=0,122 \\
& W 9=\frac{3}{9+2+7+6+7+4+5+6+3}=0,061
\end{aligned}
$$

Kemudian dicari vektor S terhadap Semua nilai Kriteria yang sudah dilakukan perubahan kedalam bentuk angka, seperti berikut:

$$
\begin{aligned}
S 1=\left(7^{0,183}\right) & +\left(3^{-0,040}\right)+\left(3^{0,142}\right)+\left(3^{0,122}\right)+\left(7^{0,142}\right)+\left(7^{0,081}\right)+\left(7^{0,102}\right)+\left(7^{0,122}\right) \\
& +\left(1^{-0,061}\right)=10,669 \\
S 2=\left(7^{0,183}\right) & +\left(1^{-0,040}\right)+\left(3^{0,142}\right)+\left(7^{0,122}\right)+\left(7^{0,142}\right)+\left(7^{0,081}\right)+\left(7^{0,102}\right)+\left(7^{0,122}\right) \\
& +\left(7^{-0,061}\right)=10,6 \\
S 3=\left(5^{0,183}\right) & +\left(3^{-0,040}\right)+\left(3^{0,142}\right)+\left(5^{0,122}\right)+\left(7^{0,142}\right)+\left(7^{0,081}\right)+\left(7^{0,102}\right)+\left(7^{0,122}\right) \\
& +\left(3^{-0,061}\right)=10,592 \\
S 4=\left(7^{0,183}\right) & +\left(1^{-0,040}\right)+\left(3^{0,142}\right)+\left(5^{0,122}\right)+\left(7^{0,142}\right)+\left(7^{0,081}\right)+\left(1^{0,102}\right)+\left(7^{0,122}\right) \\
& +\left(7^{-0,061}\right)=10,454 \\
& +\left(3^{-0,040}\right)+\left(3^{0,142}\right)+\left(7^{0,122}\right)+\left(7^{0,142}\right)+\left(7^{0,081}\right)+\left(7^{0,102}\right)+\left(3^{0,122}\right) \\
& +\left(7^{-0,061}\right)=10,557 \\
& +\left(3^{-0,040}\right)+\left(3^{0,142}\right)+\left(5^{0,122}\right)+\left(7^{0,142}\right)+\left(7^{0,081}\right)+\left(7^{0,102}\right)+\left(7^{0,122}\right) \\
& +\left(7^{-0,061}\right)=10,465 \\
S 6=\left(3^{0,183}\right) & \\
& +\left(5^{-0,040}\right)+\left(1^{0,142}\right)+\left(5^{0,122}\right)+\left(7^{0,142}\right)+\left(7^{0,081}\right)+\left(7^{0,102}\right)+\left(7^{0,122}\right) \\
& +\left(7^{-0,061}\right)=10,442
\end{aligned}
$$

Selanjutnya akan dicari nilai vektor V yang digunakan untuk mencari hasil akhir dari perhitungan

$$
\begin{gathered}
V=\frac{s}{\sum k} \\
V 1=\frac{10,669}{9}=1,185, V 2=\frac{10,6}{9}=1,178, V 3=\frac{10,592}{9}=1,176,
\end{gathered}
$$


Hal : $15-23$

$$
\begin{gathered}
V 4=\frac{10,454}{9}=1,161, V 5=\frac{10,557}{9}=1,173, V 6=\frac{10,465}{9}=1,162 \\
V 7=\frac{10,442}{9}=1,160
\end{gathered}
$$

Selanjutnya dibuatkan berdasarkan urutan dari hasil tertinggi ke hasil terendah, seperti berikut:

Tabel 4.4 Hasil Perengkingan

\begin{tabular}{|c|c|c|c|}
\hline NO & Kode Ikan & Nilai & Rangking \\
\hline $\mathbf{1}$ & IK_001 & 1,185 & $\mathbf{1}$ \\
\hline $\mathbf{2}$ & IK_002 & 1,178 & $\mathbf{2}$ \\
\hline $\mathbf{3}$ & IK_003 & 1,176 & $\mathbf{3}$ \\
\hline $\mathbf{4}$ & IK_005 & 1,173 & $\mathbf{4}$ \\
\hline $\mathbf{5}$ & IK_006 & 1,162 & $\mathbf{5}$ \\
\hline $\mathbf{6}$ & IK_004 & 1,161 & $\mathbf{6}$ \\
\hline $\mathbf{7}$ & IK_007 & 1,160 & $\mathbf{7}$ \\
\hline
\end{tabular}

Selanjutnya akan dibuatkan hasil keputusan dari perengkingan tersebut, dengan ketentuan $>=1,170$ berkualitas, $<1,170$ Tidak Berkualitas. Sehingga menghasilkan keputusan sebagai berikut:

Tabel 4.5 Hasil Keputusan

\begin{tabular}{|c|c|c|c|}
\hline NO & Kode Ikan & Nilai & Keputusan \\
\hline $\mathbf{1}$ & IK_001 & 1,185 & Berkualitas \\
\hline $\mathbf{2}$ & IK_002 & 1,178 & Berkualitas \\
\hline $\mathbf{3}$ & IK_003 & 1,176 & Berkualitas \\
\hline $\mathbf{4}$ & IK_005 & 1,173 & Berkualitas \\
\hline $\mathbf{5}$ & IK_006 & 1,162 & Tidak Berkualitas \\
\hline $\mathbf{6}$ & IK_004 & 1,161 & Tidak Berkualitas \\
\hline $\mathbf{7}$ & IK_007 & 1,160 & Tidak Berkualitas \\
\hline
\end{tabular}

\section{SIMPULAN}

Dari penulisan penelitian ini mulai dari tahapan analisa permasalahan yang ada hingga pengujian sistem yang baru dirancang maka dapat diambil beberapa kesimpulan, yaitu :

1. Hasil penerapan Sistem Pengambilan Keputusan ini mampu melakukan penyimpanan dan melakukan pencarian data dengan cepat dan mudah, sehingga dapat mempermudah user untuk memperoleh keputusan menentukan kualitas bibit ikan lele yang unggul dan tidak unggul dengan cepat.

2. Sistem Keputusan ini memberikan penilaian berdasarkan kriteria yang terdapat pada bibit ikan lele, dimana kita bisa mencocokan penilaian terhadap kriteria yang terlihat pada bibit ikan lele yang akan digunakan sebagai pertimbangan dalam pendukung keputusan.

3. Sistem pengambilan keputusan dengan metode Weighted Product ini dapat memberikan solusi untuk menyelesaikan permasalahan dalam pemilihan jenis bibit ikan lele apakah berkualitas atau tidak, sehingga keputusan yang didapatkan sesuai dengan sasaran yang tepat. 
Hal : $15-23$

\section{UCAPAN TERIMAKASIH}

Terima kasih untuk semua pihak yang sudah berkontribusi terhadap penelitian ini, smoga hasil penelitian ini dapat bermamfaat bagi semuanya..

\section{DAFTAR PUSTAKA}

[1] Nurjannah, N., Arifin, Z., \& Khairina, D. M. (2015). Sistem Pendukung Keputusan Pembelian Sepeda Motor Dengan Metode Weighted Product. J. Inform. Mulawarman, 10(2), 2-6.

[2] Manahan, O. (2016). Perancangan Dan Pembuatan Sistem Pendukung Keputusan Penentuan Karyawan Terbaik Dengan Metode Saw Pada Pt Iss Indonesia Cabang Medan. Jurnal Mantik Penusa, 19(1).

[3] Basri, B. (2017). Metode Weightd Product (Wp) Dalam Sistem Pendukung Keputusan Penerimaan Beasiswa Prestasi. Jurnal Insypro (Information System And Processing), 2(1).

[4] Aini, N., \& Agus, F. (2017). Penerapan Metode Weighted Product Dan Analytic Hierarchy Process Untuk Pemilihan Koperasi Berprestasi. Jurnal Infotel, 9(2), 220230.

[5] Sitio, M. H. F., Jubaedah, D., \& Syaifudin, M. (2017). Kelangsungan Hidup Dan Pertumbuhan Benih Ikan Lele (Clarias Sp.) Pada Salinitas Media Yang Berbeda. Jurnal Akuakultur Rawa Indonesia, 5(1), 83-96. 